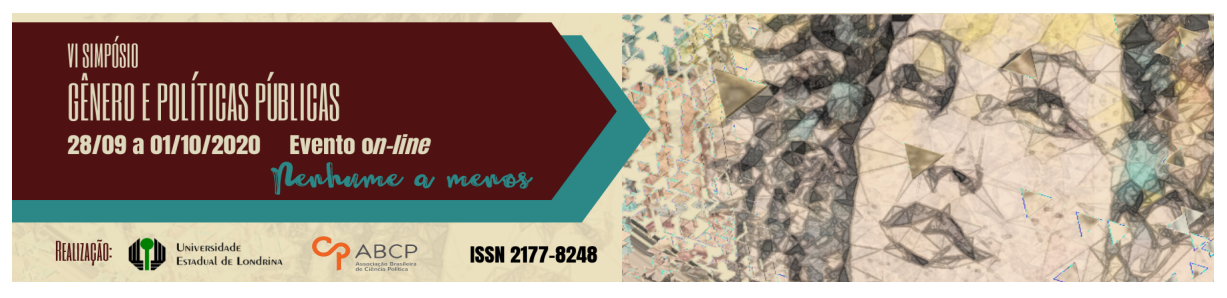

\title{
Educação infantil e divisão sexual do trabalho: qual o lugar da mulher trabalhadora?
}

Mariana Silveira dos Santos Rosa ${ }^{1}$; Idorlene da Silva Hoepers ${ }^{2}$

\section{Resumo}

Este trabalho discute a omissão do Estado no seu dever de garantir educação gratuita para as crianças pequenas, expressada pela insuficiência de vagas em creches públicas. Esta omissão está diretamente relacionada à condição da mulher trabalhadora que se vê obrigada a dividir suas atividades cotidianas entre o trabalho doméstico e o trabalho fora de casa. Pretende-se contribuir para discussões relacionadas à luta da mulher trabalhadora pela emancipação de sua classe, provocando reflexões acerca de suas necessidades e de sua realidade concreta. Este trabalho pretende demonstrar como as políticas de Estado relacionadas à educação infantil excluem parte das crianças, principalmente as originárias de famílias trabalhadoras, agindo no sentido de reproduzir a exploração de trabalhadores no sistema capitalista.

Palavras-chave: educação infantil; trabalho; mulher.

\section{Child education and sexual division of labor: what is the place of working women?}

\section{Abstract}

${ }^{1}$ IFC. Graduada em Pedagogia pela UFSC. E-mail: marianassrosa@yahoo.com.br.

2 IFC. Doutora em Educação pela UNIVALI. E-mail: idorlene.hoepers@ifc.edu.br.

GT 18 - Políticas públicas de gênero no Brasil do século XXI: avanços e desafios 
This paper discusses the State's omission in its duty to guarantee free education for young children, expressed by the insufficiency of places in public daycare centers. This omission is related to the condition of the working woman who is forced to divide her daily activities between domestic work and work outside the home. It is intended to contribute to implicate the struggle of working women for the emancipation of their class, causing reflections on their needs and their concrete reality. This work intends to demonstrate how the State policies related to early childhood education exclude part of the children, mainly as coming from working families, acting to reproduce an exploitation of workers in the capitalist system.

Keywords: child education; work; woman.

\section{Introdução}

Este trabalho é resultante de projeto de pesquisa que vem sendo realizada em nível de mestrado, no Programa de pós-graduação em Educação (PPGE) do Instituto Federal Catarinense (IFC). O estudo será realizado tendo como referência a rede pública municipal de ensino de Florianópolis (SC), mais especificamente Núcleos de Educação Infantil Municipal (NEIM's). Em tempo, é importante ressaltar que devido à pandemia da Covid-19, não foi ainda possível realizar pesquisa de campo; ou seja, as discussões aqui apresentadas referem-se à pesquisa bibliográfica e documental realizada até o momento.

A pesquisa em andamento discute a omissão do Estado no seu dever de garantir educação gratuita para as crianças pequenas, expressada pela insuficiência de vagas em creches públicas. Neste trabalho pretendemos problematizar os impactos das políticas públicas relacionadas ao oferecimento de vagas em unidades de educação infantil na vida de mulheres trabalhadoras. Deste modo, fazendo a opção por uma abordagem materialista-histórica, será possível demonstrar como as políticas públicas de Estado relacionadas à educação infantil excluem parte das crianças, principalmente as originárias de famílias trabalhadoras, agindo no sentido de reproduzir a exploração de trabalhadores no sistema capitalista. 


\section{O direito à educação infantil}

Quando o número de vagas oferecidas em instituições públicas de educação infantil é inferior à população de crianças com idades entre zero e cinco anos, são as famílias da classe trabalhadora, especialmente as mulheres mães que vivem do trabalho, que sofrem as consequências. $\mathrm{O}$ direito da criança pequena à educação infantil em creches e préescolas públicas representa a responsabilidade do Estado no cuidado e na educação destas crianças. Tais responsabilidades são compartilhadas com as famílias, pois de acordo com a Constituição Federal (1988) o Estado tem o dever de garantir às crianças de até cinco anos de idade o acesso à educação infantil. Em 1996 a Lei de Diretrizes e Bases (LDB) declarou a educação escolar pública como uma obrigação do Estado, que deve garantir educação infantil gratuita às crianças de até cinco anos de idade, além das outras etapas da educação básica. Ainda segundo a LDB, a educação infantil deve complementar a ação educativa da família e da comunidade na qual a criança está inserida.

Neste sentido, é necessário superar o entendimento de que a educação das crianças pequenas é um processo pelo qual apenas suas famílias precisam ser responsabilizadas. Estes deveres foram reforçados em 2009, com a resolução que fixa as Diretrizes Curriculares Nacionais para a Educação Infantil (DCNEI), de acordo com a qual, além de pública e gratuita, a educação infantil oferecida deve ser de qualidade e sem requisito de seleção. É importante ressaltar que os termos creche e pré-escola não se referem a instituições com caráteres distintos em relação ao serviço oferecido e ao público atendido. A LDB de 1996 passou a incluir a creche como uma etapa da Educação Básica, rompendo a segregação que esta modalidade da educação infantil enfrentava diante da pré-escola e mesmo dos ensinos fundamental e médio. Segundo Kuhlmann Jr. (2001, p. 55):

A vinculação de creches e pré-escolas ao nosso sistema educacional representa uma conquista do ponto de vista da superação de uma situação 
administrativa que mantinha um segmento de instituições educacionais específico para os pobres, segregado do ensino regular, com todo o peso dos preconceitos relacionados a isso.

A LDB define a educação infantil como primeira etapa da educação básica e a divide em dois níveis de acordo com a faixa etária atendida: creche para crianças de zero a três anos, pré-escola para as crianças de quatro a cinco anos. Deste modo, segundo Kuhlmann Jr. (2001), a creche perde o estigma de instituição destinada a pessoas pobres, sendo possível se ater à educação de crianças bem pequenas. Antes desta legislação era comum chamar de creche qualquer instituição (formal ou não) que oferecesse cuidados a crianças pequenas, em sua maioria provenientes da classe trabalhadora, enquanto préescolas eram as instituições destinadas à educação das crianças originárias da classe dominante.

A partir das DCNEI, profissionais e estudiosos da educação infantil se dedicaram a popularizar o termo educar-e-cuidar, afirmando a indissociabilidade do cuidado e da educação de crianças pequenas nas instituições de educação infantil e garantindo às famílias que procuram uma creche ou uma pré-escola a segurança de que suas crianças recebem educação em sua integralidade. A expansão do atendimento educacional para crianças no Brasil começou a ser observada a partir de 1960, quando o número de instituições de educação infantil cresceu de forma significativa pelo país. Stemmer (2012) apresenta alguns fatores que podem ter contribuído para esse crescimento, dentre os quais aparecem

desenvolvimento do emprego industrial e dos grandes centros urbanos [...]; ampliação do trabalho feminino nos setores médios, levando também a classe média a procurar instituições educacionais para os seus filhos; eclosão do movimento de lutas por creches, no final dos anos 1970; reivindicação de vários setores sociais (STEMMER, 2012, p. 22). 
Tais fatores podem ter ligação direta com a origem das políticas públicas relacionadas à educação infantil de forma centralizada entre união, estados e municípios. Segundo Kramer (2006), estas políticas públicas começaram a tomar forma em 1975, com a criação da Coordenação de Educação Pré-Escolar, pelo Ministério de Educação e Cultura (MEC, atualmente Ministério da Educação).

\section{Educação infantil em Florianópolis}

Em Florianópolis, a rede pública municipal de educação infantil começou a se estruturar a partir de 1976, com a elaboração do Projeto Núcleos de Educação Infantil pela então Secretaria de Educação, Saúde e Assistência Social (SESAS), destinado inicialmente a crianças com quatro a seis anos de idade. O primeiro Núcleo de Educação Infantil (NEI) foi inaugurado ainda em 1976, na Coloninha, uma localidade da área continental de Florianópolis marcada pela carência econômica, prestando atendimento a cerca de 90 crianças com idades entre quatro e sete anos. A partir de 1979 o NEI Coloninha começou a atender crianças com menos de três anos, faixa etária até então não atendida pela prefeitura, e passou a se chamar Creche Professora Maria Barreiros, a primeira creche municipal de Florianópolis (OSTETTO, 2000).

A partir daí a Rede Municipal de Educação Infantil de Florianópolis começou a crescer e se expandir por todo o município. Em 1996 existiam 63 espaços de educação infantil, prestando atendimento a quase cinco mil crianças (MAISTRO, 1997). Segundo dados do Plano Municipal de Educação (PME), em 2014 existiam 78 unidades públicas municipais de educação infantil, além de 16 unidades conveniadas que prestavam este serviço, totalizando 94 unidades. Atualmente a Prefeitura Municipal de Florianópolis lista 103 unidades educativas que atendem à primeira etapa da educação básica, sendo 13 conveniadas e 90 NEIM's (FLORIANÓPOLIS, 2020). No entanto, as mudanças na legislação e a expansão da rede em todo o Brasil não se concretizaram 
na universalização do atendimento em creches e pré-escolas públicas para todas as crianças.

As vagas oferecidas nas unidades educativas de educação infantil das redes de ensino não são suficientes para atender às necessidades das famílias. Segundo dados da última Pesquisa Nacional por Amostra de Domicílios (PNAD), realizada em 2017 pelo Instituto Brasileiro do Geografia e Estatística (IBGE), a taxa de escolarização das crianças de zero a três anos não chega a 33\%, e mesmo na faixa etária obrigatória (quatro a cinco anos) cerca de $9 \%$ ainda estão fora das unidades educativas (IBGE, 2017). Em 2018 havia cerca de 1.330 crianças de zero a cinco anos nas listas de espera das unidades de educação infantil da Rede Pública Municipal de Ensino, que oferecia em torno de 15 mil vagas em turno parcial ou integral (FLORIANÓPOLIS, 2018). ${ }^{3}$

Se levarmos em conta os dados do último Censo (IBGE), segundo os quais em 2010 havia mais de 22 mil crianças com até quatro anos de idade no município de Florianópolis, deduzimos que cerca de seis mil crianças não apareciam nos dados da SME (nem como matriculadas nem nas listas de espera das unidades educativas municipais). ${ }^{4}$ Ou seja, por algum motivo as famílias destas crianças não buscaram vagas na rede municipal de educação infantil, seja por não necessitarem, seja por não terem tido acesso aos procedimentos necessários para o processo inscrição, ou mesmo por não terem condições de apresentar todas as documentações exigidas para este processo.

\section{O lugar da mulher da classe trabalhadora}

3 Segundo a Resolução n 5 de 17 de dezembro de 2009 (CEB/CNE), que fixa as
Diretrizes Curriculares Nacionais para a Educação Infantil: "É considerada Educação
Infantil em tempo parcial, a jornada de, no mínimo, quatro horas diárias e, em tempo
integral, a jornada com duração igual ou superior a sete horas diárias, compreendendo
o tempo total que a criança permanece na instituição".
$4 \quad$ Disponível
<https://censo2010.ibge.gov.br/sinopse/webservice/frm_piramide.php?codigo=4205
$40>$. 
Essa situação de escassez de vagas impacta principalmente as famílias trabalhadoras, pois se suas crianças não estiverem frequentando unidades públicas de educação infantil ou se estiverem frequentando em período parcial, caberá às famílias a responsabilidade por compensar a ausência do Estado no compartilhamento da educação destas crianças. Ou seja, tanto no caso em que o atendimento não é oferecido pelo Estado quanto no caso em que o atendimento é oferecido em período parcial, as consequências para a família afetam diretamente a situação de trabalho de seus membros.

Há situações em que uma das pessoas responsáveis pela criança precisa sair do mundo do trabalho social para se dedicar exclusivamente à sua educação e ao seu cuidado no período em que ela não está na instituição de educação infantil, passando a contribuir preferencialmente para a reprodução da família por meio do trabalho doméstico, que não é remunerado. Há situações nas quais um ou mais responsáveis pela criança se vêm obrigados a flexibilizar ou reduzir suas jornadas de trabalho (tendo por consequência a diminuição de seus salários), ou até mesmo a buscarem empregos onde são submetidos a situações de precarização, para que possam se dedicar à criança no período que deveria ser destinado ao descanso. Há ainda situações nas quais os responsáveis pela criança recorrem a pessoas que possam substituí-los, na maior parte das vezes uma mulher de parentesco próximo (irmã mais velha, tia, avó), ou até mesmo uma vizinha com a qual a família tenha alguma relação afetiva e/ou de confiança.

Nas sociedades capitalistas ocidentais é comum atribuir a responsabilidade pelos cuidados das crianças pequenas apenas às suas mães. A naturalização dos cuidados como uma tarefa feminina é explicada por Engels (2002), quando apresenta a família monogâmica patriarcal como uma das bases do surgimento da propriedade privada e do Estado. Sendo assim, partimos da hipótese de que geralmente é a mãe da criança quem precisa adaptar sua situação de trabalho à oferta de vagas (ou ausência delas) nas instituições de educação infantil públicas. Esta mulher precisa ou flexibilizar sua jornada de trabalho fora 
de casa para se dedicar aos cuidados dos filhos no período em que não estão sendo atendidos pelo Estado, ou se dedicar exclusivamente ao trabalho doméstico, o que inclui os cuidados das crianças que não são contempladas com vagas integrais nas creches e pré-escolas públicas. Nestes casos a mulher que antes era reconhecida como trabalhadora pois estava inserida no mundo do trabalho, fazendo parte diretamente do processo de produção - passa a ser vista como dona-de-casa, e não como desempregada, realizando o trabalho reprodutivo normalmente atribuído às mulheres pela sociedade.

A naturalização do trabalho feminino, que parte da convenção de que há tarefas intrínsecas à condição de ser mulher (limpar os espaços, cuidar das crianças, cozinhar, lavar, costurar, entre outras), tem relação com o processo de exploração que sustenta a sociedade capitalista. Dentro da divisão social do trabalho também se manifesta a divisão sexual do trabalho, que atribui às mulheres tarefas consideradas de menor importância, seja dentro da fábrica, seja no ambiente doméstico (CISNE, 2015). Na divisão sexual do trabalho o homem é responsável pela maior parte da produção social, vendendo sua força de trabalho para os proprietários dos meios de produção, enquanto a mulher se dedica aos trabalhos domésticos ao mesmo tempo em que também vende sua força de trabalho. ${ }^{5}$

O cuidado com as crianças pequenas faz parte do conjunto de tarefas normalmente atribuídas pela sociedade às mulheres. Segundo Toledo (2017), homens e mulheres são igualmente versáteis para a realização de qualquer tipo de tarefa, mas a sociedade de classes conformou as mulheres aos interesses do capital, ou seja, ao exercício de tarefas que não exigem qualificação. Deste modo a mulher se responsabiliza pela reprodução da força de trabalho, “[...] se ocupando das tarefas domésticas, com as quais supre as deficiências do Estado em

5 Tais dados podem ser constatados em pesquisa do IBGE (2018) relacionada a estatísticas de gênero, segundo a qual em 2016 as mulheres dedicaram cerca de 18 horas semanais aos cuidados de pessoas e afazeres domésticos, enquanto os homens dedicaram 10 horas semanais a estas mesmas tarefas. 
relação aos serviços públicos, receba salários precários, e sirva de mão de obra barata e descartável." (TOLEDO, 2017, p. 71). No caso das famílias trabalhadoras brasileiras geralmente recai sobre a mãe a total responsabilidade de cuidar dos filhos nos casos em que o Estado se omite deste dever. Entendemos, portanto, que existe uma omissão do Estado no seu dever de garantir educação gratuita para as crianças pequenas, resultando na duplicidade do ato do trabalho (ANTUNES, 2009). Este tema remete à condição da mulher trabalhadora, que se vê obrigada a dividir suas atividades cotidianas entre o trabalho doméstico e o trabalho fora de casa, sendo esta mulher

duplamente explorada pelo capital: desde logo por exercer, no espaço público, seu trabalho produtivo no âmbito fabril. Mas, no universo da vida privada, ela consome horas decisivas no trabalho doméstico, com o que possibilita (ao mesmo capital) a sua reprodução, nessa esfera de trabalho não diretamente mercantil, em que se criam as condições indispensáveis para a reprodução da força de trabalho de seus maridos, filhos/as e de si própria. (ANTUNES, 2009, p. 108).

\section{Educação infantil e marxismo}

Partimos da compreensão de que a sociedade capitalista, dividida entre classes antagônicas, está marcada por lutas e embates de diferentes naturezas. Estes embates, frequentes principalmente nos âmbitos econômico e político, provocam impactos na educação. Segundo Kramer (2006, p. 30):

Supor que os problemas econômicos podem ser superados sem modificações nas relações de produção existentes, ou seja, sem mudanças na infraestrutura econômica, reflete uma concepção idealista e liberal do mundo. Significa, ainda, que a sociedade de classes não é vista enquanto tal. É falsa a crença na educação, na escola ou na pré-escola, como motores da revolução social, porque esta acontece quando são transformadas as relações de produção existentes, e 
o papel da educação (no caso, também da educação pré-escolar) pode ser o de contribuir para manter ou mudar uma dada realidade social em função de sua conjuntura política e econômica, não o de ser responsável pela transformação dessa conjuntura.

Para aprofundar a discussão acerca da classe trabalhadora e da condição da mulher na sociedade dividida em classes, é necessário compreender o conceito de trabalho - além de outros conceitos relacionados a esta categoria central nos estudos marxistas. Entendemos o trabalho como a ação realizada pelo ser humano sobre o meio, de forma deliberada, planejada e consciente; características que diferenciam a ação humana das atividades que outros animais realizam em contato com a natureza. O ser humano, ao atuar "sobre a natureza externa e modificando-a por meio desse movimento, ele modifica, ao mesmo tempo, sua própria natureza." (MARX, 2013, p. 255). Enquanto a ação de outros animais sobre o meio é realizada de forma instintiva ou mecânica, o trabalho é um processo complexo de aprendizagem, pois permite o desenvolvimento de técnicas e tecnologia úteis à humanidade. Por meio do trabalho homens e mulheres criam suas próprias ferramentas, diferenciando-se dos demais animais, modificam os materiais que encontram disponíveis na natureza, e, segundo Marx (2013, p. 256):

No final do processo de trabalho, chega-se a um resultado que já estava presente na representação do trabalhador no início do processo, portanto, um resultado que já existia idealmente. Isso não significa que ele se limite a uma alteração da forma do elemento natural; ele realiza neste último, ao mesmo tempo, seu objetivo, que ele sabe que determina, como lei, o tipo e o modo de sua atividade e ao qual ele tem de subordinar sua vontade.

A partir do conceito de trabalho é possível compreender mais profundamente quem é o sujeito da classe trabalhadora (quem é a pessoa que faz parte desta classe). Segundo Antunes (2009, p. 103, grifos do autor): 
Uma noção ampliada de classe trabalhadora inclui, então, todos aqueles e aquelas que vendem sua força de trabalho em troca de salário, incorporando, além do proletariado industrial, dos assalariados do setor de serviços, também o proletariado rural, que vende sua força de trabalho para o capital. ${ }^{6}$

Entendemos que o acesso das crianças da classe trabalhadora à educação infantil pública e gratuita tem uma profunda relação com a situação de trabalho das mulheres desta classe. Por esta razão recorremos a teóricos marxistas que contribuem para o desenvolvimento dos conceitos de classe, de família e de divisão sexual do trabalho, buscando ainda elementos que contribuem para discutir temas como classe trabalhadora, mulher da classe trabalhadora, gênero, estrutura familiar no capitalismo e mãe trabalhadora. Por meio da pesquisa bibliográfica até então realizada percebemos que Engels (2002), Saffioti (2013), Toledo (2017) e Antunes (2009) oferecem uma consistente fundamentação teórica para o desenvolvimento desses conceitos. Tais discussões são essenciais para compreendermos as políticas públicas educacionais relacionadas à infância, assim como o papel do Estado na elaboração destas políticas.

Consideramos importante compreender que a concepção de infância não pode estar descolada da origem da criança, assim como das relações sociais e das interações estabelecidas em torno deste sujeito. Diante deste pressuposto, percebemos que Saviani (2003) e Arce e Jacomeli (2012), sustentados na pedagogia histórico-crítica, contribuem com este entendimento. Além destes, Faria e Palhares (2007) nos ajudam a conceber uma profunda caracterização da educação infantil no Brasil, assim como a relação desta etapa da educação básica com a classe trabalhadora. Para tratarmos mais especificamente do acesso à educação infantil pública e gratuita pelas crianças da classe trabalhadora nos sustentamos em Campos, Rosemberg e Ferreira (1995),

\footnotetext{
${ }^{6}$ Neste conceito também podem ser incluídos trabalhadores e trabalhadoras informais e pessoas desempregadas. Para dar conta das especificidades da classe trabalhadora contemporânea, Antunes (2009) utiliza a expressão classe-que-vive-do-trabalho.
} 
que discutem os temas em âmbito nacional. As discussões em torno da rede pública de educação infantil do município de Florianópolis são abordadas por Ostetto (2000) e Füllgraf (2001; 2008), cujas reflexões têm início na constituição desta rede, a partir da inauguração do NEI Coloninha.

Apoiamo-nos ainda em Kuhlmann Jr. (2001) e Freitas e Monarcha (2011) com o objetivo de conhecer a trajetória da educação infantil desde o seu surgimento - com creches destinadas às crianças das famílias operárias - até sua inclusão como etapa da educação básica, passando pelas mudanças de concepções e de caráter deste tipo de serviço. E entendendo a necessidade de partirmos do contexto social para compreender a criança e a condição infantil, nos fundamentamos com Kramer (2006), a partir da qual pudemos refletir acerca do papel da educação na sociedade de classes, estabelecendo relações entre as políticas públicas voltadas à educação infantil e a situação das famílias trabalhadoras.

O referencial teórico apresentado nos aponta para o papel cumprido pelo Estado como instrumento de dominação de classe. Nas políticas educacionais para a educação infantil é o Estado quem legitima a exclusão das crianças, por meio da criação de critérios que não garantem a universalidade da oferta de vagas, atuando também como instrumento de opressão contra as mulheres. Estes entendimentos são reforçados com as contribuições de Engels (2002) e Lênin (2017). Ademais, o debate acerca do Estado exige uma melhor compreensão acerca da dinâmica e da reprodução do capitalismo, encontrada em Marx e Engels (2007) e em Marx (2013), atualizados em Antunes (2009), que fundamenta a compreensão acerca da sociedade capitalista atual, suas mudanças e o processo de intensificação e precarização do trabalho.

\section{Considerações finais}


Partimos da compreensão de que as políticas de Estado voltadas à educação infantil excluem parte das crianças, principalmente as originárias de famílias trabalhadoras. Ao analisar os impactos para a classe trabalhadora da escassez de vagas integrais em unidades de educação infantil, pudemos compreender como a inserção social e econômica da mulher no mundo do trabalho se relaciona à disponibilidade de vagas públicas e gratuitas em unidades de educação infantil. Analisando elementos de política social em torno das políticas públicas relacionadas ao cuidado e à educação de crianças, foi possível discutir questões relacionadas às necessidades das mulheres trabalhadoras, partindo do trabalho como categoria de análise. Deste modo compreendemos que a omissão do Estado na oferta de vagas em creches públicas contribui para o controle da classe dominante sobre a classe trabalhadora. Segundo Iasi (2007, p. 40-41):

A partir do momento em que o trabalhador se apercebe do caráter das relações sociais em que está inserido, coloca-se a necessidade de buscar uma transformação. No entanto, nesse momento do processo de consciência, já não é suficiente saber que é necessário mudar a sociedade, destruir o capitalismo, mas como fazê-lo e o que colocar no lugar. A concepção da potencialidade da classe, a consciência da possibilidade de vitória, é parte integrante da consciência de classe.

Tal entendimento exige que assumamos uma postura radical em relação à exploração a qual a classe trabalhadora é submetida na sociedade capitalista, contribuindo para seu processo de emancipação. Partindo da existência de critérios de seleção, percebemos que o direito à educação infantil pública e gratuita não é acessado pela totalidade das crianças da classe trabalhadora, fato que demonstra a omissão do Estado no cumprimento de seu dever. Afinal, o estabelecimento de critérios significa que não há vagas para todas as crianças, ou seja, que o Estado está se omitindo de garantir para todas as crianças e suas famílias o direito à educação infantil pública e gratuita. Portanto, entendemos que por meio destas políticas o Estado mantém, legitima e 
aprofunda as opressões e a exploração sobre a mulher trabalhadora, favorecendo a continuidade da exploração de uma classe sobre a outra.

\section{Referências}

ANTUNES, Ricardo. Os sentidos do trabalho: ensaio sobre a afirmação e a negação do trabalho. 2a. ed. São Paulo, SP: Boitempo, 2009.

ARCE, Alessandra; JACOMELI, Mara Regina Martins. Educação infantil versus educação escolar?: entre as (des)escolarização e a precarização do trabalho pedagógico nas salas de aula. Campinas, SP: Autores Associados, 2012.

BRASIL. Constituição da República Federativa do Brasil. Promulgada em 5 de outubro de 1988. Disponível em:

<http://www.planalto.gov.br/ccivil_03/Constituicao/Constituicao. htm>. Acesso em: 25 ago. 2020.

BRASIL. Lei $N^{\circ}$ 9.394, de 20 de dezembro de 1996. Estabelece as Diretrizes e Bases da Educação nacional. Disponível em:

<http://www.planalto.gov.br/ccivil_03/LEIS/L9394.htm>. Acesso em: 25 ago. 2020.

BRASIL. Ministério da Educação. CNE/CEB. Resolução $n^{0}$ 5, de 17 de dezembro de 2009. Fixa as Diretrizes Curriculares Nacionais para a Educação Infantil. Disponível em:

<http://portal.mec.gov.br/index.php?option=com_docman\&view= download\&alias=2298-rceb005-09\&category_slug=dezembro-2009pdf\&Itemid=30192>. Acesso em: 25 ago. 2020.

CAMPOS, Maria Malta; ROSEMBERG, Fúlvia; FERREIRA, Isabel M. Creches e pré-escolas no Brasil. 2a. ed. São Paulo: Cortez; Fundação Carlos Chagas, 1995.

CISNE, Mirla. Gênero, divisão sexual do trabalho e Serviço Social. 2. ed. São Paulo: Outras Expressões, 2015. 
ENGELS, Friedrich. A origem da família, da propriedade privada e do Estado. São Paulo: Centauro, 2002.

FARIA, Ana Lúcia Goulart; PALHARES, Marina Silveira (Org.). Educação infantil pós-LDB: rumos e desafios. 6. ed. Campinas, SP: Autores Associados, 2007.

FLORIANÓPOLIS, Prefeitura Municipal. Secretaria Municipal de Educação. Conveniadas. Disponível em: <http:/ / www.pmf.sc.gov.br/entidades/educa/index.php?cms=con veniadas\&menu=4\&submenuid=139>. Acesso em: 25 ago. 2020.

FLORIANÓPOLIS, Prefeitura Municipal. Secretaria Municipal de Educação. Núcleos de Educação Infantil Municipais. Disponível em: <http://www.pmf.sc.gov.br/entidades/educa/index.php?cms=nuc leos+de+educacao+infantil + municipais \&menu $=4 \&$ submenuid=139> . Acesso em: 25 ago. 2020.

FLORIANÓPOLIS, Prefeitura Municipal. Secretaria Municipal de Educação. Prefeitura reduz número de crianças na fila de espera em creche, 01 fev. 2008. Disponível em:

<http://portal.pmf.sc.gov.br/entidades/educa/index.php?pagina= notpagina\&noti=19293>. Acesso em: 25 ago. 2020.

FREITAS, Marcos Cezar de; MONARCHA, Carlos. História social da infância no Brasil. 8. ed. São Paulo: Cortez, 2011.

FÜLLGRAF, Jodete Bayer Gomes. A infância de papel e o papel da infância. 2001. 170 p. Dissertação (Mestrado em Educação) - Centro de Ciências da Educação, Universidade Federal de Santa Catarina, Florianópolis, 2001.

FÜLLGRAF, Jodete Bayer Gomes. O lugar da educação infantil na sociedade contemporânea. Ciências E Letras, n. 43, p. 25-40, jan. 2008.

IASI, Mauro Luis. Ensaios sobre consciência e emancipação. São Paulo: Expressão Popular, 2007.

IBGE. Estatísticas de gênero: indicadores sociais das mulheres no Brasil. Estudos e Pesquisas, n. 38, p. 1-12, 2018.

IBGE. Pesquisa Nacional por Amostra de Domicílios Contínua (PNAD). Educação 2017. Disponível em: 
<https://biblioteca.ibge.gov.br/visualizacao/livros/liv101576_infor mativo.pdf>. Acesso em: 25 ago. 2020.

KRAMER, Sônia. A politica do pré-escolar no Brasil: a arte do disfarce. 8. ed. São Paulo: Cortez, 2006.

KUHLMANN JUNIOR, Moysés. Infância e educação infantil: uma abordagem histórica. 2. ed. Porto Alegre: Mediação, 2001.

LÊNIN, Vladímir Ilitch. O Estado e a revolução: a doutrina do marxismo sobre o Estado e as tarefas do proletariado na revolução. São Paulo: Boitempo, 2017.

MAISTRO, Maria Aparecida. As relações creche-famílias: um estudo de caso. 1997. 190 p. Dissertação (Mestrado em Educação) - Centro de Ciências da Educação, Universidade Federal de Santa Catarina, Florianópolis, 1997.

MARX, Karl. O Capital: Crítica da economia política. Livro I: O processo de produção do capital. São Paulo: Boitempo, 2013.

MARX, Karl; ENGELS, Friedrich. A ideologia alemã. São Paulo: Boitempo, 2007.

OSTETTO, Luciana Esmeralda. Educação infantil em Florianópolis. Florianópolis: Cidade Futura, 2000.

SAFFIOTI, Heleieth. A mulher na sociedade de classes: mito e realidade. 3 . ed. São Paulo: Expressão Popular, 2013.

SAVIANI, Dermeval. Pedagogia histórico-crítica: primeiras aproximações. 8. ed. Campinas, SP: Autores Associados, 2003.

STEMMER, Márcia Regina Goulart. Educação Infantil: gênese e perspectivas. In: ARCE, Alessandra; JACOMELI, Mara Regina Martins. Educação infantil versus educação escolar?: entre as (des)escolarização e a precarização do trabalho pedagógico nas salas de aula. Campinas, SP: Autores Associados, 2012.

TOLEDO, Cecília. Gênero e classe. São Paulo: Sundermann, 2017.L 